\title{
PERFORMA EMBEDED BALOK PRECAST TIPE PIN WELDED PLATE PADA MOMEN MAKSIMUM
}

\author{
A. Rudi Hermawan ${ }^{(1)}$,Eka Sasmita Mulya ${ }^{(2)}$ \\ ${ }^{1,2}$ Dosen Jurusan Teknik Sipil, Politeknik Negeri Jakarta, Kampus UI Depok, Telp. 021-7270036, email: \\ arudihermawan@gmail.com,ekamulya66@yahoo.com
}

\begin{abstract}
ABSTRAK
Pengujian performa embeded balok Precast yang telah dilakukan menghasilkan beberapa data sebagai berikut (a) hasil kuat tekan beton (compressive strength) rerata yang dihasilkan adalah 434,22 kg/cm2 (b) hasil uji tarik rerata antara plat embedded dan plat sambung adalah 398,36 Mpa (c) hasil kuat tarik rerata antara plat sambung dengan tulangan D13 terhadaap kekuatan tarik plat adalah 465.70 Mpa dan terhadap kekuatan tarik tulangan adalah 570,01 Mpa (d) hasil kuat tarik tulangan D13 adalah 633 Mpa dan hasil kuat leleh (yield strength) adalah $441 \mathrm{Mpa}$ (e) hasil kuat tarik plat tebal 4,57 mm adalah $451 \mathrm{Mpa}$ dan kuat leleh (yield strength) adalah 331,2 Mpa.Untuk sambungan las perlu adanya perbaikan kualitas las agar tidak terjadi hasil las yang berongga dan mengakibatkan melemahkan kuat Tarik dari las itu sendiri
\end{abstract}

Kata kunci: reinforcement, tensile strength, embedded, yield strength

\section{PENDAHULUAN}

Keuntungan tipe sambungan ini adalah para konstruktor tidak perlu menggunakan baut atau alat mekanik lainnya untuk menyambung antara dua balok, selain itu dengan menggunakan tipe Pin, konstruktor hanya tinggal memasukan antar balok lalu dilakukan pengelasan karena tidak perlu lagi melevelisasi balok yang biasa dilakukan pada umumnya. Dengan demikian maka waktu pelaksanaan akan lebih singkat dan biaya konstruksi akan dapat di minimalkan.

Penelitian mengenai plat welded sudah pernah dilakukan pada tahun 1993 oleh Ugur Ersoy, Tugrul Tankut pada PCI Jurnal Paper membahas mengenai sambungan pada daerah sendi plastis dengan menggunakan plat embedded yang disambung dengan plat sambung yang di las dan di berikan pada bagian atas dan bawah balok.

Kemudian pada tahun 2013 yang lalu juga telah dilakukan penelitian mengenai sambungan welded plat oleh Mario E. Rodríguez, Miguel Torres-Matos pada PCI Jurnal Paper membahas mengenai sambungan antara balok dengan kolom dengan menggunakan plat embedded yang dihubungkan dengan besi tulangan yang di las dan diberikan hanya pada bagian bawah balok sedangkan pada bagian atas balok menggunakan Cast in place.

Perbedaan yang bisa diuraikan antara rencana penelitian ini dengan penelitian yang sudah dilakukan oleh Ugur Ersoy, Tugrul Tankut dan Mario E. Rodríguez, Miguel Torres-Matos di atas adalah (a) pada penelitian ini daerah yang akan dijadikan obyek adalah daerah tengah bentang balok (b) tipe atau sistim yang dilakukan pada penlitian ini adalah Pin Welded Joint seperti yang sudah dijelaskan di atas dan diilustrasikan di halaman berikutnya. 


\section{Teori}

Balok adalah elemen lentur pada struktur yang mempunyai fungsi sebagai transfer beban ke elemen kolom. Beban-beban yang ada,akan mengakibatkan terjadinya momen lentur dan gaya geser pada balok tersebut. Untuk itu dengan sistim sambungan pin welded plate diharapkan balok tersebut mempunyai kekuatan yang tidak berbeda dari kekuatan balok konvensionalnya (desain awalnya). Gaya-gaya pada splices ditransfer melalui beton disekeliling antara tulangan yang bersangkutan. Transfer gaya tersebut terjadi melalui kekuatan bonding antara beton dengan tulangan itu sendiri (ACI Code, PCI ) . Integritas dari elemen balok dengan sistim sambungan pin welded plate tergantung dari bonding antara beton dengan tulangan pada perpanjangan tulangan yang ada serta yang utama adalah kekuatan dari baut itu sendiri dalam menahan tarik akibat momen yang ada.

\section{Compresion Splices}

Besarnya gaya yang terjadi pada daerah compression bonded nonprestressed tidak sama dibandingkan dengan kasus pada tension bonded nonprestressed. Dimana gaya yang terjadi pada tension bonded nonprestressed akan lebih besar dibandingkan dengan compression bonded nonprestressed. Perpanjangan tulangan bonded nonprestressed pada daerah compression bonded nonprestressed dapat diambil sebesar :

ld $=\left(\frac{f y . . d b}{4 \cdot \sqrt{f c^{\prime}}}\right)>200 \mathrm{~mm}^{(2,3)}$

Dimana:

fy $\quad=$ Tegangan leleh ( Mpa )

$\mathrm{db} \quad=$ Nominal diameter tulangan

$\mathrm{fc}^{\prime} \quad=$ Mutu beton $(\mathrm{MPa})$

\section{Tension Bonded Nonprestressed}

Hal yang sangat menentukan kekuatan lentur dari balok Precast sistim welded embedded middle wet joint adalah pada sistim ikatan (bonded) antara beton dengan tulangan,welded antara pelat embedded dengan pelat sambungnya dan kekuatan dari pelat itu sendiri. Untuk itu ACI dan SKNI serta PCI telah mengatur untuk panjang daerah ikatan (bonded) antara beton dan tulangan, yaitu:

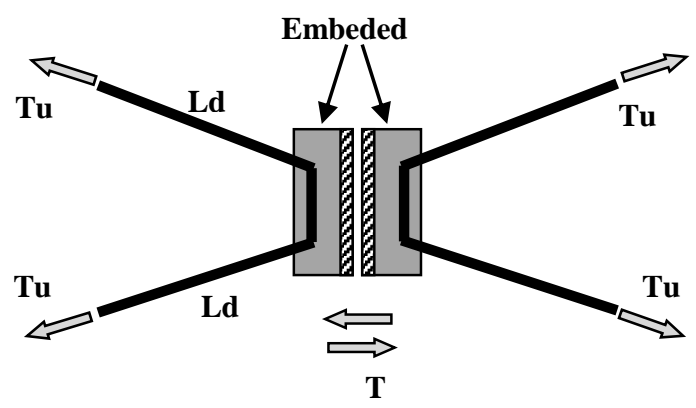

Gambar 1. Embeded

$\mathrm{Ld}=\left(\frac{18 \cdot f y \cdot \alpha \cdot \beta \cdot \lambda \cdot d b}{25 \cdot \sqrt{f c^{\prime}}}\right)>300 \mathrm{~mm}$ 
Dimana :

$$
\begin{array}{ll}
\text { fy } & =\text { Tegangan leleh }(\text { Mpa }) \\
\alpha & =\text { Reinforcement location factor } \\
\beta & =\text { Coating factor }
\end{array}
$$

$$
\begin{aligned}
\lambda \quad= & \text { Ligthweigth aggregate } \\
& \text { concrete factor } \\
\mathrm{db} \quad= & \text { Nominal diameter tulangan } \\
\mathrm{fc} & =\text { Mutu beton }(\mathrm{MPa})
\end{aligned}
$$

\section{METODE PENELITIAN}

\section{Prototype Benda Uji}

Prototype dari benda uji adalah benda uji berbentuk balok dengan panjang $320 \mathrm{~cm}$, lebar balok $20 \mathrm{~cm}$ dan tinggi balok $30 \mathrm{~cm}$. Benda uji ini akan didesain dengan menggunakan tulangan berdiameter $13 \mathrm{~mm}$ untuk tulangan lenturnya dan diameter 8 mm (ASTM 615) untuk tulangan gesernya. Untuk mutu beton digunakan mutu beton rencana adalah K300. Jumlah benda uji yang akan dilakukan dalam penelitian ini dapat dilihat pada tabel di bawah ini.

Tabel 1. Jumlah Benda Uji

\begin{tabular}{llll}
\hline No & Uraian Penlitian & Jumlah Benda Uji & Output \\
\hline 1 & Uji Kuat Tekan Beton & $5 \mathrm{bh}$ & Performa Joint \\
2 & Uji Kuat Tarik Baja Tulangan & $5 \mathrm{bh}$ & Performa Joint \\
3 & Uji Kuat Tarik Baja Plat & $5 \mathrm{bh}$ & Performa Joint \\
4 & Uji Bonding Baja Tulangan dengan Beton & $5 \mathrm{bh}$ & Performa Joint \\
5 & Uji Tarik Sambungan Las antara Plat & $5 \mathrm{bh}$ & Performa Joint \\
& Embeded dengan tulangan & & \\
6 & Uji Tarik Plat sambung dengan plat embeded & $5 \mathrm{bh}$ & Performa Joint \\
\hline
\end{tabular}
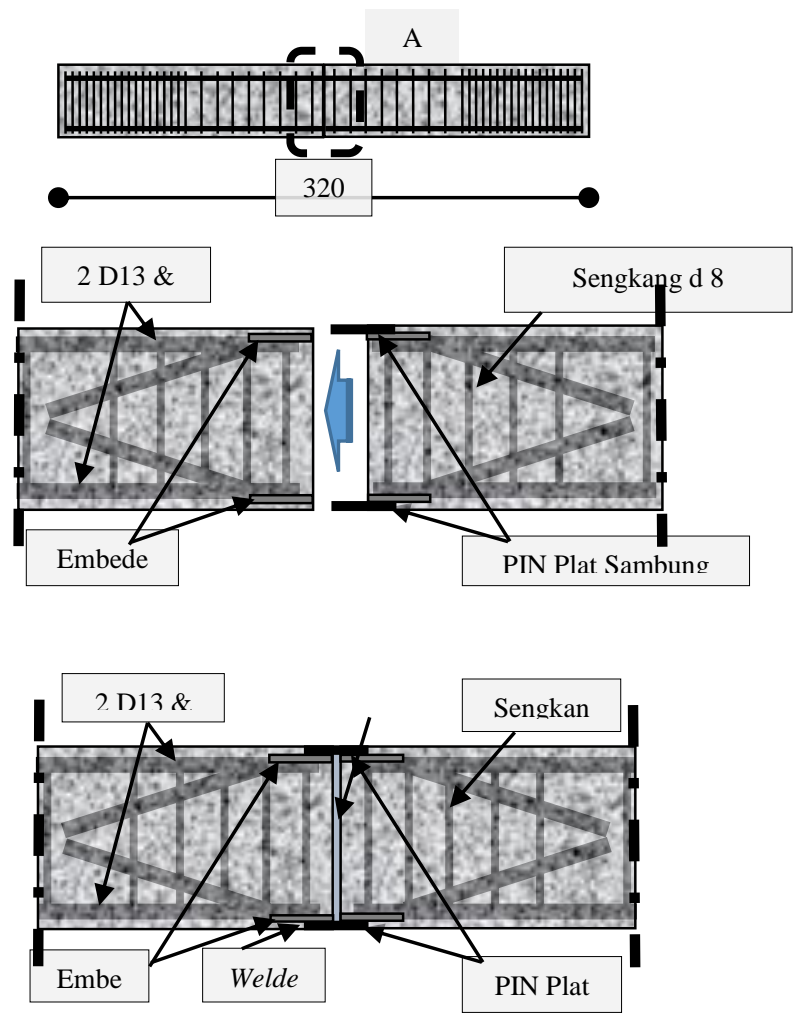

Gambar 2. Prototype Benda Uji Balok Precast 


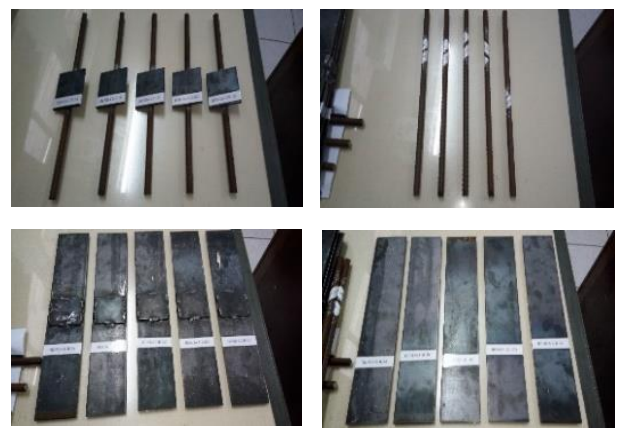

Gambar 3. Prototype Benda Elemen Sambung

\section{Metode Pengujian}

Untuk metoda pengujian tarik elemen sambungan balok dapat dilihat seperti di bawah ini:

Tarik

BendaUji

Tarik

Gambar 4. Metode uji Elemen Sambung

Untuk metoda pengujian lentur balok mengacu pada peraturan ASTM C78-02, peneliti akan menggunakan alat UTM (Universal Testing Machine) dengan kondisi seperti gambar dibawah ini.

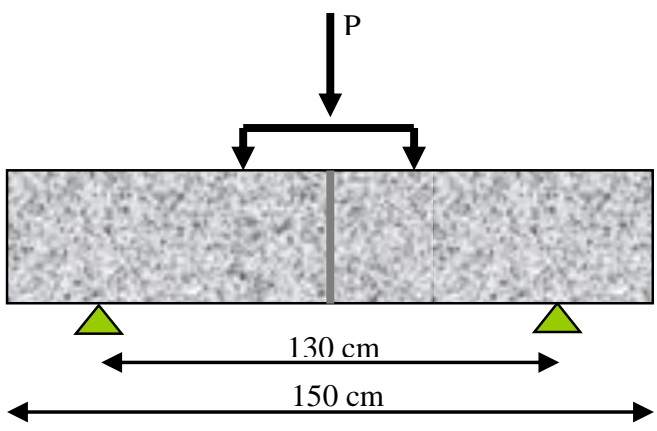

Gambar 5. Ilustrasi Pembebanan Balok

\section{HASIL DAN PEMBAHASAN}

Pengujian yang telah dilakukan telah menghasilkan beberapa data sebagai berikut (a) hasil kuat tekan beton (compressive strength) rerata yang dihasilkan adalah 434,22 $\mathrm{kg} / \mathrm{cm} 2$ (b) hasil uji tarik rerata antara plat embedded dan plat sambung adalah 398,36 Mpa (c) hasil kuat tarik rerata antara plat sambung dengan tulangan D13 terhadaap kekuatan tarik plat adalah 465.70 Mpa dan terhadap kekuatan tarik tulangan adalah 570,01 Mpa (d) hasil kuat tarik tulangan D13 adalah 633 Mpa dan hasil kuat leleh (yield strength) adalah $441 \mathrm{Mpa}$ (e) hasil kuat tarik plat tebal 4,5 mm adalah $451 \mathrm{Mpa}$ dan kuat leleh (yield strength) adalah 331,2 Mpa. Untuk hasil uji tarik las antara plat 
sambung dengan plat embedded dan uji tarik las antara plat sambung dengan tulangan diameter 13 ada beberapa sambungan yang memenuhi ketentuan perhitungan teoritis ditandai dengan putusnya bagian pada tulangan dan ada beberapa sambungan yang hasilnya tidak sesuai dengan teoritis hal itu dikarenakan adanya luasan las yang dihasilkan tidak sesuai dengan perhitungan dimensi las teoritis. Untuk lebih jelasnya dapat dilihat tabel di bawah ini.

Tabel 2. Hasil Kuat Tekan Beton

\begin{tabular}{ccccccccc}
\hline \multirow{2}{*}{ NO } & BENDA UJI & LUAS & BERAT & TGL & TGL & \multicolumn{2}{l}{ BEBAN } & MUTU \\
\cline { 9 - 10 } \cline { 8 - 9 } & & $\mathrm{cm}^{2}$ & $\mathrm{~g}$ & COR & UJI & $\mathrm{kg}$ & $\mathrm{kg} / \mathrm{cm}^{2}$ \\
\hline \multirow{2}{*}{1} & Benda Uji 1A & 225 & 8147 & $4.3 \mathrm{E}+04$ & $4.3 \mathrm{E}+04$ & $9.9 \mathrm{E}+04$ & 440.0 \\
2 & Benda Uji 1B & 225 & 8067 & $4.3 \mathrm{E}+04$ & $4.3 \mathrm{E}+04$ & $1.1 \mathrm{E}+05$ & 480.0 \\
3 & Benda Uji 1C & 225 & 7911 & $4.3 \mathrm{E}+04$ & $4.3 \mathrm{E}+04$ & $9.0 \mathrm{E}+04$ & 400.0 \\
4 & Benda Uji 2A & 225 & 8097 & $4.3 \mathrm{E}+04$ & $4.3 \mathrm{E}+04$ & $9.4 \mathrm{E}+04$ & 417.8 \\
5 & Benda Uji 2B & 225 & 8050 & $4.3 \mathrm{E}+04$ & $4.3 \mathrm{E}+04$ & $9.8 \mathrm{E}+04$ & 433.3 \\
\hline
\end{tabular}

Tabel 3. Hasil Uji Tarik Plat Sambung dan Plat Embeded

\begin{tabular}{ccccccccccccccc}
\hline $\begin{array}{l}\mathrm{N} \\
\mathrm{O}\end{array}$ & BENDA UJI & $\begin{array}{r}\text { MAX. } \\
\text { LOAD }\end{array}$ & $\begin{array}{c}\text { T.P. } \\
\text { JOINT }\end{array}$ & \multicolumn{2}{c}{ L.LAS KA. } & L.LAS & $\begin{array}{c}\text { L.LAS } \\
\text { KI }\end{array}$ & L.LAS & F.KA & F.KI & KET. \\
\hline & & $\mathrm{kg}$ & $\mathrm{mm}$ & $\mathrm{mm}$ & $\mathrm{mm}$ & $\mathrm{mm}$ & $\mathrm{mm}$ & $\mathrm{mm}$ & $\mathrm{mm}$ & Mpa & Mpa & \\
\hline 1 & Benda Uji 1A & 7350 & 4.54 & 20.25 & 23.00 & 23.25 & 22.75 & 21.25 & 67.25 & 462.99 & 437.17 & Lepas di las \\
2 & Benda Uji 1B & 5700 & 4.54 & 21.75 & 20.50 & 23.50 & 22.75 & 22.25 & 68.50 & 509.50 & 332.85 & Lepas di las \\
3 & Benda Uji 1C & 7200 & 4.54 & 20.00 & 24.25 & 23.75 & 27.25 & 21.00 & 72.00 & 420.44 & 400.00 & Lepas di las \\
4 & Benda Uji 1D & 7350 & 4.54 & 22.00 & 26.25 & 20.75 & 23.75 & 22.75 & 67.25 & 424.55 & 437.17 & Lepas di las \\
5 & Benda Uji 1E & 6250 & 4.54 & 21.25 & 21.75 & 23.50 & 19.75 & 21.75 & 65.00 & 373.13 & 384.62 & Lepas di las \\
\hline
\end{tabular}

Tabel 4. Hasil Uji Tarik Tulangan dan Plat Sambung Terhadap Plat

\begin{tabular}{|c|c|c|c|c|c|c|c|c|c|c|c|}
\hline $\begin{array}{l}\mathrm{N} \\
\mathrm{O}\end{array}$ & BENDA UJI & $\begin{array}{l}\text { MAX. } \\
\text { LOAD }\end{array}$ & $\begin{array}{l}\text { T.P.J } \\
\text { OINT }\end{array}$ & L.LAS & KA. & $\begin{array}{l}\text { L.LA } \\
\text { S }\end{array}$ & $\begin{array}{l}\text { L.LA } \\
\text { S KI }\end{array}$ & $\begin{array}{c}\text { L.LA } \\
\mathrm{S}\end{array}$ & F.KA & F.KI & KET \\
\hline & & $\mathrm{kg}$ & $\mathrm{mm}$ & $\mathrm{mm}$ & $\mathrm{mm}$ & $\mathrm{mm}$ & $\mathrm{mm}$ & $\mathrm{mm}$ & Mpa & Mpa & \\
\hline 1 & Benda Uji 1A & 7050 & 4.54 & 33.25 & 32.25 & 33.00 & 31.50 & 64.50 & 430.53 & 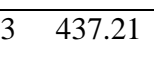 & Lepas di las \\
\hline 2 & Benda Uji 1B & 7500 & 4.54 & 32.50 & 31.75 & 31.00 & 30.50 & 61.50 & 466.93 & 487.80 & Lepas di las \\
\hline 3 & Benda Uji 1C & 6900 & 4.54 & 32.25 & 32.25 & 31.50 & 31.25 & 62.75 & 427.91 & 439.84 & Lepas di las \\
\hline 4 & Benda Uji 1D & 7500 & 4.54 & 30.75 & 32.00 & 33.50 & 32.50 & 66.00 & 478.09 & 454.55 & Putus di Tul. \\
\hline 5 & Benda Uji 1E & 8050 & 4.54 & 32.00 & 29.25 & 30.50 & 32.75 & 63.25 & 525.71 & 509.09 & Putus di Tul. \\
\hline
\end{tabular}


Tabel 5. Hasil Uji Tarik Tulangan dan Plat Sambung Terhadap Plat Terhadap Tulangan

\begin{tabular}{cccccccccccc}
\hline $\begin{array}{l}\mathrm{N} \\
\mathrm{O}\end{array}$ & BENDA UJI & $\begin{array}{c}\text { MAX. } \\
\text { LOAD }\end{array}$ & $\begin{array}{c}\text { T.P. } \\
\text { JOINT }\end{array}$ & \multicolumn{2}{c}{ L.LAS KA. } & $\begin{array}{c}\text { L.LAS } \\
\text { KI }\end{array}$ & L.LAS & F.KA & F.KI & KET \\
\hline & & $\mathrm{kg}$ & $\mathrm{mm}$ & $\mathrm{mm}$ & $\mathrm{mm}$ & $\mathrm{mm}$ & $\mathrm{mm}$ & Mpa & Mpa & \\
\hline 1 & Benda Uji 1A & 7050 & 4.54 & 33.25 & 33.00 & 31.50 & 64.50 & 543.05 & 543.05 & Lepas di las \\
2 & Benda Uji 1B & 7500 & 4.54 & 32.50 & 31.00 & 30.50 & 61.50 & 577.71 & 577.71 & Lepas di las \\
3 & Benda Uji 1C & 6900 & 4.54 & 32.25 & 31.50 & 31.25 & 62.75 & 531.49 & 531.49 & Lepas di las \\
4 & Benda Uji 1D & 7500 & 4.54 & 30.75 & 33.50 & 32.50 & 66.00 & 577.71 & 577.71 & Putus di Tul. \\
5 & Benda Uji 1E & 8050 & 4.54 & 32.00 & 30.50 & 32.75 & 63.25 & 620.08 & 620.08 & Putus di Tul. \\
\hline
\end{tabular}

Tabel 6. Hasil Uji Tarik Plat t.4,56 mm

\begin{tabular}{cccccccc}
\hline NO & BENDA UJI & $\mathrm{t}$ & LEBAR & LUAS & L & F. TARIK & F.LELEH \\
\hline & & $\mathrm{mm}$ & $\mathrm{mm}$ & $\mathrm{mm} 2$ & $\mathrm{~mm}$ & $\mathrm{Mpa}$ & Mpa \\
\hline 1 & Benda Uji 3A & 4.56 & 12.50 & 57.00 & 50 & 402 & 284 \\
2 & Benda Uji 3B & 4.56 & 12.46 & 56.82 & 50 & 470 & 353 \\
3 & Benda Uji 3C & 4.5 & 12.33 & 55.49 & 50 & 461 & 343 \\
4 & Benda Uji 3D & 4.5 & 12.47 & 56.12 & 50 & 461 & 343 \\
5 & Benda Uji 3E & 4.56 & 12.42 & 56.64 & 50 & 461 & 333 \\
\hline & & 4.54 & & & & 451 & 331.2 \\
\hline
\end{tabular}

Tabel 7. Hasil Uji Tarik Tulangan D.13 mm

\begin{tabular}{rrccccc}
\hline NO & BENDA UJI & DIM. UKUR & LUAS & L UKUR & K.TARIK & \multicolumn{2}{c}{ B.LELEH } \\
\hline & & $\mathrm{mm}$ & $\mathrm{mm} 2$ & $\mathrm{~mm}$ & $\mathrm{Mpa}$ & Mpa \\
\hline 1 & Benda Uji 4A & 8.92 & 62.46 & 45 & 627 & 441 \\
2 & Benda Uji 4B & 8.96 & 63.02 & 45 & 637 & 441 \\
3 & Benda Uji 4C & 9.03 & 64.01 & 45 & 647 & 461 \\
4 & Benda Uji 4D & 9.11 & 65.15 & 45 & 627 & 431 \\
5 & Benda Uji 4E & 9.10 & 65.01 & 45 & 627 & 431 \\
\hline
\end{tabular}


Tabel 8. Hasil Uji Tarik Bonding Tulangan D 13 mm- Beton

\begin{tabular}{|c|c|c|c|c|c|c|c|c|}
\hline NO & BENDA UJI & DIA TUL & $\mathrm{LD}$ & A & P LELEH & PU TARIK & F LELEH & FU TARIK \\
\hline & & $\mathrm{mm}$ & $\mathrm{mm}$ & $\mathrm{mm} 2$ & $\mathrm{~N}$ & $\mathrm{~N}$ & $\mathrm{Mpa}$ & $\mathrm{Mpa}$ \\
\hline 1 & B.U 1 & 12.86 & 501.81 & 129.82 & 52189.2 & $75,537.00$ & 402.00 & 581.85 \\
\hline 2 & B.U 2 & 12.86 & 501.81 & 129.82 & 54739.8 & $78,480.00$ & 421.65 & 604.52 \\
\hline 3 & B.U 3 & 12.86 & 501.81 & 129.82 & 55328.4 & $78,480.00$ & 426.18 & 604.52 \\
\hline 4 & B.U 4 & 12.86 & 501.81 & 129.82 & 54739.8 & $77,499.00$ & 421.65 & 596.96 \\
\hline \multirow[t]{2}{*}{5} & B.U 5 & 12.86 & 501.81 & 129.82 & 54543.6 & $77,891.00$ & 420.14 & 599.98 \\
\hline & & & & & $54,308.2$ & $77,577.40$ & 418.32 & 597.56 \\
\hline
\end{tabular}

Tabel 9. Hasil Uji Tarik Bonding Tulangan D 13 mm- Beton

\begin{tabular}{rlccccccc}
\hline NO & BENDA UJI & DIA TUL & LD & A & P LELEH & PU TARIK & F LELEH & FU TARIK \\
\hline & & $\mathrm{mm}$ & $\mathrm{mm}$ & $\mathrm{mm} 2$ & $\mathrm{~N}$ & $\mathrm{~N}$ & $\mathrm{Mpa}$ & Mpa \\
\hline 1 & B.U 1 & 12.86 & 501.81 & 129.82 & 52189.2 & $75,537.00$ & 402.00 & 581.85 \\
2 & B.U 2 & 12.86 & 501.81 & 129.82 & 54739.8 & $78,480.00$ & 421.65 & 604.52 \\
3 & B.U 3 & 12.86 & 501.81 & 129.82 & 55328.4 & $78,480.00$ & 426.18 & 604.52 \\
& & & & & & & & \\
4 & B.U 4 & 12.86 & 501.81 & 129.82 & 54739.8 & $77,499.00$ & 421.65 & 596.96 \\
5 & B.U 5 & 12.86 & 501.81 & 129.82 & 54543.6 & $77,891.00$ & 420.14 & 599.98 \\
\hline & & & & & & & & \\
\end{tabular}

\section{KESIMPULAN}

Kesimpulan dari penelitian ini adalah sebagai berikut :

1. Untuk hasil uji tarik las antara plat sambung dengan plat embedded dan uji tarik las antara plat sambung dengan tulangan diameter 13 ada beberapa sambungan yang memenuhi ketentuan perhitungan teoritis ditandai dengan putusnya bagian pada tulangan dan ada beberapa sambungan yang hasilnya tidak sesuai dengan teoritis hal itu dikarenakan adanya luasan las yang dihasilkan tidak sesuai dengan perhitungan dimensi las teoritis

2. Kekuatan tarik putus plat adalah $451 \mathrm{Mpa}$ dan kekuatan tarik leleh plat adalah 351,2 Mpa dan kekuatan tarik putus tulangan D13 adalah 633 Mpa dan kekuatan tarik leleh tulangan adalah $441 \mathrm{Mpa}$. 


\section{DAFTAR PUSTAKA}

[1] ACI Committee 318, 2014, Building Code Requirments for Structure and Commentary,American Concrete Institute, Detroit

[2] Nadim,M and Manaser,A, 2008, Structural Concrete : Theory and Design ,USA, John Wiley and Sons,

[3] Rodríguez. dan Torres M, Summer 2013 , "Seismic Behavior of type of welded precast concrete beam- colum connection, PCI Journal Paper ,Vol.58, Issue: 3, Page number: 81-94

[4] SNI 03-2847-2013, Standar Nasional Indonesia ,Tata Cara Perhitungan Struktur Beton Untuk Bangunan Gedung, Bandung,2013

[5] Ugur Ersoy and Tankut Tugrul, July-August 1993," Precast Concrete Members with Welded Plate Connections Under Reversed Cyclic Loading “, PCI Jurnal Paper, Volume 38, Issue: 4, Page number: 94-100 